\title{
Les enjeux des marchés du colza et de ses dérivés
}

Oléagineux, Corps Gras, Lipides. Volume 10, Numéro 3, 178-86, Mai 2003, Colza : enjeux et nouvelles synergies de la recherche, ÉCONOMIE

Auteur(s) : Yves DRONNE, INRA ESR PAM rue Adolphe Bobierre, CS 61103 F-35011 Rennes-Cedex Tél. : 33 (0) 223485407 Fax : 33 (0) $223485380<y$ dronneroazhon.inra.fr> .

Author(s) : Yves DRONNE

Résumé : Le colza représente dans I'Union Européenne (UE) la première graine oléagineuse produite localement, la principale huile végétale produite et consommée dans cette zone, et une source de protéines pour l'alimentation animale de grande importance à côté du tourteau de soja essentiellement importé sous forme de graines et de tourteaux à partir de l'Amérique du Nord et du Sud. Alors que les marchés potentiels des co-produits du colza, de plus en plus diversifiés, demeurent très importants pour l'alimentation humaine, animale et les usages techniques, la production n'augmente que faiblement depuis un certain nombre d'années en raison d'une part de la difficile compétition de cette culture par rapports aux autres spéculations végétales de l'UE et notamment au blé, et d'autre part de la forte pression sur les prix qu'exerce l'environnement international, où dominent de plus en plus les tourteaux de soja pour les matières riches en protéines et les huiles de palme et de soja pour les matières grasses végétales. Cette situation est d'abord en relation avec I'évolution de la Politique Agricole Commune (PAC) où, depuis la mise en place de I'Agenda 2000, les graines oléagineuses ont subi un découplage " vers le bas " avec un abaissement des aides directes pour ces produits au niveau de celles attribuées aux céréales, alors qu'aux Etats-Unis, depuis le Fair Act de 1996, le soja comme les autres oléagineux a bénéficié d'un découplage "vers le haut ", avec I'attribution à ces produits des mêmes avantages que pour les céréales. La transformation du soutien par les prix aux producteurs de soja et autres oléagineux en soutien des revenus par la création des Marketing Loans a contribué à un effondrement des prix mondiaux des huiles et tourteaux à partir de 1998 qui a pénalisé l'ensemble des producteurs mondiaux d'oléagineux et notamment ceux de I'UE. Cette évolution des prix des produits du colza a été renforcée par le très fort développement des productions de soja au Brésil et en Argentine, ainsi que d'huile de palme en Malaisie et en Indonésie. Le colza continue malgré tout à bénéficier de nombreux atouts pour l'agriculture européenne. Face à des produits d'importation qui sont de plus en plus obtenus à partir de graines OGM et dont la traçabilité est de plus en plus difficile à garantir, les consommateurs et utilisateurs en alimentation animale sont de plus en plus sensibilisés à l'intérêt que présentent cette huile et ce tourteau. Maintenant que I'UE n'est plus soumise aux limites de surface en oléagineux héritées de Blair House, il est important que le colza puisse continuer à bénéficier d'importants efforts de recherche pour que son rendement évolue au moins au même rythme que celui des céréales et que la mise sur le marché de nouvelles variétés avec des compositions améliorées en huile et en protéines lui permette d'être plus compétitif au niveau des différents créneaux d'utilisation. Il est également important que l'intérêt de cette culture au niveau environnemental, notamment comme instrument de diversification des rotations, soit pleinement reconnu par les pouvoirs publics de I'UE. 
Summary : Rapeseed is in European Union (EU) the first oilseed produced locally, the first vegetable oil produced and used in this area, and an important protein feed for animal production, beside soybean meals that are mainly imported from North and South America in form of seeds and meals. Though more and more diversified, potential markets for rape co-products, remain very important for feed, food and technical uses, crops have been increasing very slowly for many years because of competition with other plant productions in the EU, especially wheat, and because of the important pressure on world markets prices where soybean meal is more and more the dominant product for high protein feed and soybean and palm oils for vegetable fats. This situation is in relation with the evolution of Common Agricultural Policy (CAP) in which, for the application of Agenda 2000, oilseeds have been submitted to a "down" decouplage with a reduction of the subsidies for these products to the level of cereals, while in the United States, for application of the Fair Act in 1996, oilseeds have benefited an "upper" decouplage with attribution of the advantages previously reserved to cereals. The transformation of price support into income support for soybeans and other oilseeds with of marketing loans contributed to a collapse in international meals and oil prices that had large impact on foreign oilseeds producers including those of the EU. This evolution of rapeseed co-product prices has been aggravated by huge increases of soybean productions in Brazil and Argentina and palm oil in Malaysia and Indonesia. Despite these problems rapeseed still has many advantages for European agriculture. Facing imported products which come more and more from GMO seeds and for which traceability is increasingly difficult to guarantee, consumers and users for animal feeding can be sensible to the guaranties that present this oil and this meal. Now that the EU is no longer submitted to oilseed maximum areas inherited from Blair House, it is important that rapeseed carries on benefiting from important research efforts so that its yield can grow at the same rate as cereal yield, and that the obtention and cultivation of new varieties with improved composition in oil and protein, can make these products more competitive to soybean in their various fields of utilisation. It is also important that the interest of this crop in an environmental point of view, for instance for diversification of rotations, can be completely recognised by the European policy.

Mots-clés : colza, tourteau, non alimentaire, commerce mondial

Keywords : rapeseed meal, non food, international trade

\section{ARTICLE}

Auteur(s) : Yves DRONNE

INRA ESR PAM rue Adolphe Bobierre, CS 61103 F-35011 Rennes-Cedex

Tél. : 33 (0) 223485407

Fax : 33 (0) 223485380

<ydronne@roazhon.inra.fr>

Le colza est depuis de nombreuses années l'un des oléagineux les plus produits et échangés dans le monde sous forme de graines, d'huiles et de tourteaux. Au sein de I'Union Européenne (UE), la superficie de cette culture ne progresse que lentement depuis une dizaine d'années en raison de conditions diverses liées au contexte international des prix du complexe oléagineux - et notamment 
du soja en relation avec l'évolution de la politique agricole des Etats-Unis-, aux accords internationaux signés notamment à Blair House dans le cadre de I'Organisation Mondiale du Commerce (OMC) et aux modifications de la Politique Agricole Commune (PAC) de I'UE. Le colza conserve néanmoins un rôle fondamental - notamment du fait du recul en Europe des protéagineux et du tournesol et de la régression du soja - en tant que culture de diversification pour les agriculteurs, source majeure de protéines concentrées pour l'élevage et l'industrie des aliments composés, et source d'huile pour la consommation humaine et les industries agro-alimentaires, et de plus en plus, source majeure pour usages non alimentaires et notamment énergétiques. Au niveau international, même si cette culture est loin de représenter en tonnage l'équivalent du soja ou du palme, elle confère à I'UE une position significative en tant que second producteur mondial de cette graine juste derrière la Chine, avec des tonnages souvent très voisins. Même si l'UE demeure globalement un importateur net de tourteaux de colza et, en général, de graines, elle joue cependant un rôle important dans l'approvisionnement en graines de certains pays étrangers pour leur industrie de trituration, et en huiles de colza pour leur consommation humaine. Face à un marché mondial des oléagineux de plus en plus dominé par le soja produit aux Etats-Unis et en Amérique du Sud (principalement au Brésil et en Argentine), où la place des variétés issues des biotechnologies ne cesse de croître, le colza a donc dans I'UE un rôle spécifique à jouer, non seulement pour les agriculteurs, mais pour l'ensemble de la filière, y compris les consommateurs de plus en plus sensibilisés aux intérêts nutritionnels de cette huile et à la plus grande facilité de traçabilité de ces co-produits communautaires, comparativement à celle des produits d'importations. Compte tenu des évolutions récentes de cette Organisation Commune de Marché (OCM) et des projets de réforme de la PAC, l'avenir de cette filière qui, en termes de prix, subit très largement l'influence de l'environnement international, dépendra largement de l'attention que lui porteront les pouvoirs publics et des nouveaux progrès que permettra la recherche publique et privée en termes de rendement et de coûts de production par rapport aux autres cultures comme les céréales, ainsi que d'amélioration de la composition des graines, des huiles et des tourteaux pour répondre à un ensemble diversifié de marchés potentiels dans I'UE, voire à l'exportation.

\section{Le colza dans I'UE et en France}

Pour l'ensemble des oléagineux, I'UE, comme la France, présente un très important déficit. Jusqu'à la fin des années 80, on avait enregistré un important développement de ces cultures oléagineuses, grâce à la fois à des progrès importants en amélioration des plantes et techniques culturales, aux efforts des agriculteurs pour diversifier leurs productions et répondre à une importante demande intérieure en protéines et matières grasses, et aussi grâce à une réglementation communautaire relativement favorable.

En dehors des graines de coton dont la production, limitée à la Grèce et à l'Espagne, sur environ 450000 hectares (ha), représente de l'ordre de 700 à 800000 tonnes, et des graines de lin dont la production est revenue à environ 110000 tonnes sur un peu plus de 100000 hectares, la production communautaire d'oléagineux concerne essentiellement le colza et le tournesol et, à un niveau beaucoup plus limité, le soja dont la culture est pratiquement limitée à l'Italie et à la France. En 1990/91 la surface dans l'UE pour les trois principaux oléagineux atteignait 5,7 millions d'hectares (Mha) Depuis, elle a pratiquement stagné avec de fortes fluctuations selon les années en fonction de 
la conjoncture internationale et des évolutions de la PAC. Pour 2003/2004, la surface de l'UE devrait être de l'ordre de 5,3 millions d'ha soit un recul de plus de 700000 ha par rapport au record de 6,0 Mha atteint en 1994/95.

Par rapport aux céréales, la part des oléagineux dans l'UE est très faible (figure 1). Elle est passée par un maximum de $18 \%$ en 1994 et régresse depuis, avec moins de $14 \%$ en 2002/2003. En effet compte tenu des différences entre les OCM " céréales " et " oléagineux ", principalement du fait de l'absence de prix d'intervention pour ces derniers produits et de la disparition du mécanisme d'ajustement des aides depuis la mise en place de l'Agenda 2000, la rentabilité de ces cultures dépend directement des cours mondiaux. Ce secteur se trouve donc directement confronté à la baisse des cours enregistrés sur les marchés mondiaux depuis 1998/99.

Au niveau des oléagineux communautaires trois phénomènes importants sont à souligner :

\section{La croissance de la part du colza dans les oléagineux de l'UE}

Alors que, par rapport aux surfaces cultivées en 1990 de 5,6 Mha, les 15 pays actuels de I'UE enregistrent un recul de 300000 ha pour cette campagne 2003/2004 (figure 2), la surface en colza qui atteint 3,2 Mha (soit un nouveau record après le pic de 3,6 observé en 1999), marque une progression de plus d'un million d'hectares.

Ainsi la part du colza dans les superficies des trois principaux oléagineux cultivés dans l'UE est passée de moins de $40 \%$ en 1986 à plus de $60 \%$ actuellement (figure 3). Ceci s'explique principalement par le recul des surfaces en tournesol, en particulier en Espagne et en France, et, dans une moindre mesure, par la régression des superficies de soja en Italie et en France. Ces deux productions, qui se caractérisent par des rendements plus faibles et plus variables que ceux du colza, alors que les prix internationaux de ces graines sont souvent voisins, ont eu en effet beaucoup plus de mal à s'adapter aux évolution des marchés mondiaux et de la PAC. Cette évolution de l'offre contraste avec l'évolution positive de la demande globale au niveau des graines pour la trituration ainsi que des huiles et des tourteaux, demande qui est de plus en plus satisfaite par des produits d'importation.

\section{Une place importante des cultures en non alimentaire pour le colza}

Depuis la mise en place de la réglementation de l'UE autorisant la culture d'oléagineux à des fins non alimentaires sur les terres en jachère, ce type de production a connu un développement important. II concerne principalement le colza (745000 ha en 2002) et dans une bien moindre proportion le tournesol (74 000 hectares au cours de la même année).Pour le colza, la surface en non alimentaire, a fortement fluctué au cours des années en fonction des cours mondiaux des produits pétroliers, des parités du dollar par rapport à l'ECU puis l'Euro, et des prix des différentes huiles végétales. Actuellement, la part du non alimentaire représente environ $16 \%$ des surfaces totales en colza de I'UE (figure 4).

\section{La diminution de la place de la France dans l'UE et la montée de l'Allemagne}

La France et l'Allemagne (incluant la RFA et l'ex RDA avant 1991) sont, depuis le début des années 80, les deux principaux producteurs de colza parmi les 15 membres actuels de I'UE. La superficie des 13 autres pays qui avait atteint un pic d'environ un million d'hectares en 1999 ne représente plus qu'environ 750000 en 2003 (figure 5). 
La part des différents pays dans la superficie de l'UE a fortement évolué au cours du temps (figure 6). Au cours des 10 dernières années le phénomène le plus marquant est, après la période de forte croissance de la place de la France (de $24 \%$ en 1983 à $40 \%$ en 2000), le retournement de situation depuis 1996 avec la forte progression de l'Allemagne qui redevient le premier producteur de I'UE devant la France et le recul global des autres pays qui retombent en dessous des $25 \%$ après avoir atteint les $45 \%$ au milieu des années 80 .

Le nouveau rôle central de l'Allemagne, à côté de la France, sur les marchés du colza s'observe aussi en ce qui concerne la trituration et les utilisations de tourteaux et d'huiles.

\section{Le colza dans la trituration communautaire}

Le colza constitue donc une culture de première importance dans I'UE, mais c'est aussi toute la filière qui justifie l'importance de ce produit: trituration, utilisation de tourteaux et d'huile. Avec près de 31 millions de tonnes (MT), I'UE est actuellement le troisième triturateur mondial de graines oléagineuses, loin derrière les Etats-Unis et la Chine (50 MT chacun), mais devant le Brésil (27 MT) et l'Argentine (25 MT). Deux importantes caractéristiques de I'UE sont, d'une part, la diversité des graines transformées et, d'autre part, la destination essentiellement intérieure des deux co-produits obtenus (huile et tourteau).

Alors que le colza est de loin la première graine oléagineuse produite dans l'UE avec $67 \%$ du total, le soja représente la plus grande partie de cette trituration avec plus de $55 \%$. En effet, à côté de la modeste production de graines de soja de l'Italie et de la France (environ 900000 tonnes), I'UE importe des différents pays d'Amérique environ $18 \mathrm{MT}$ de ces graines. Ce tonnage qui représente environ $33 \%$ du commerce mondial de ces graines (54,6 MT en 2002) fait de I'UE le premier importateur mondial, même si la Chine, compte tenu de la croissance exponentielle de sa demande sur le marché international, est en passe de lui ravir la première place. A côté des utilisations de graines de soja communautaires ou importées pour la trituration, on doit noter l'existence d'un débouché important de ce produit (au même titre que le colza) sous forme de graines entières incorporées dans les aliments composés de différents pays européens.

Pour les graines de colza, outre un important commerce intra-communautaire principalement alimenté par la France et, à un moindre degré, le Royaume-Uni et le Danemark, il existe des flux d'échanges importants avec les pays tiers aussi bien à l'exportation qu'à l'importation, le solde étant légèrement excédentaire au cours de l'année 2002. Au cours de cette année, la trituration de colza dans I'UE représente $29 \%$ de la trituration totale. L'Allemagne représente à elle seule une trituration de 4,5 MT, soit 600000 tonnes de plus que sa production de graines de 3,9 MT, alors qu'en France, par rapport à une production de 3,3 MT, la trituration ne s'est élevée qu'à 1,5 MT. La France joue en effet un rôle important d'approvisionnement en graines de colza des industries de trituration d'autres pays européens comme l'Allemagne et I'UEBL (Union Economique Belgo-luxembourgeoise) et, dans une moindre mesure, les Pays-Bas et le Royaume-Uni. L'importance de la production française de colza dépasse donc les seuls intérêts des agriculteurs français et intéresse une grande partie de l'UE.

Le tournesol constitue la troisième graine triturée dans I'UE. La trituration de cette graine, dont le tonnage a régulièrement diminué au cours des dernières années (3,6 MT en 2002 contre 5,3 en 1998) en raison du recul des récoltes communautaires, doit de plus en plus utiliser des graines 
d'importations. Celles-ci représentent actuellement environ $38 \%$ des graines de tournesol triturées et proviennent pour l'essentiel des Pays d'Europe Centrale et Orientale (PECOs), ainsi que d'Ukraine et de Russie. Par contre, les approvisionnements en provenance de l'Argentine qui, avec environ 350000 tonnes, demeure le premier exportateur mondial devant la Hongrie, ne cesse de reculer. Globalement le déficit de I'UE en graines oléagineuses s'élève à plus de 20 MT en 2002, les importations massives de ces graines, constituées pour plus de $84 \%$ de soja, n'étant que très faiblement compensées par des exportations de colza qui représentent l'essentiel des exportations communautaires de graines oléagineuses à destination des pays tiers. Le premier intérêt de la trituration communautaire est de contribuer à la couverture des besoins en protéines concentrées de l'élevage et de l'industrie des aliments composés de I'UE. La quantité de tourteaux sortie des usines communautaires, provenant de graines locales ou importées, a représenté en 2002 environ $50 \%$ des consommations, le solde étant importé directement sous forme de tourteaux. Le tourteau de soja dont la demande n'a cessé de croître au cours des dernières années du fait notamment de l'interdiction des farines de viande et d'une nette tendance de la part de nombreux fabricants d'aliments composés à recourir de plus en plus à des formules " simplifiées " à base essentiellement de céréales (blé, maïs) et de ce tourteau, s'alignant ainsi de plus en plus sur le modèle dominant au niveau international généralement désigné comme "modèle maïs-soja ». L'industrie des aliments composés de l'UE qui, jusqu'à il y a une dizaine d'années - à la veille de la réforme Mac Sharry de la PAC - utilisait des tonnages très importants de produits de substitutions de céréales comme le manioc, le corn-gluten-feed, les pulpes d'agrumes, etc.., ainsi qu'une gamme diversifiée de sources de protéines : protéagineux, tourteaux secondaires comme le lin, le coton, le coprah, le palmiste et, plus anciennement, l'arachide, recourt de plus en plus à seulement deux matières premières (le blé et le tourteau de soja) dont les tonnages utilisés ne cessent de croître. Alors que le tourteau de soja représente en 2002 plus de $70 \%$ des tourteaux consommés, les parts $\mathrm{du}$ colza et $\mathrm{du}$ tournesol ne sont respectivement que de $13 \%$ et de $7 \%$. Pour le colza et le tournesol, il est important de souligner que la production de ces graines dans l'UE est limitée par des problèmes de compétitivité de ces cultures, liés à la réglementation communautaire actuelle, et non par l'existence de débouchés insuffisants pour ces tourteaux. En effet, en plus des tourteaux issus des unités de triturations communautaires, l'UE doit importer de l'ordre de 500000 tonnes de tourteaux de colza (environ $9 \%$ de la consommation) et 1,3 MT de tourteaux de tournesol ( $42 \%$ de la consommation). Au niveau de l'exportation de tourteaux, l'UE joue un rôle limité, ses fournitures se limitant pour l'essentiel à des ventes de tourteaux de soja à certains PECOs (principalement la Pologne, la République Tchèque et la Slovaquie). Les huiles constituent le principal axe de valorisation des diverses graines oléagineuses, à l'exception du soja pour laquelle la part du tourteau est généralement dominante compte tenu du rendement technique de cette graine en huile (environ $18 \%$ ), nettement plus faible que celui en tourteau (environ $78 \%$ ).Au niveau des huiles végétales, le colza occupe actuellement la première place dans I'UE, à la fois au niveau de la production et de la consommation. Hormis quelques huiles secondaires spécifiques comme le germe de maïs et le lin, l'UE a consommé en 2002 environ 14 MT de matières grasses végétales, ce qui représente environ 37 kilos par tête et par an pour une population de 378 millions d'habitants. Si I'on ajoute les corps gras animaux (beurre, suif, saindoux, huiles de poissons, etc.) le chiffre est de $50 \mathrm{~kg} /$ tête/an, à comparer avec un chiffre de $51 \mathrm{~kg} /$ tête/an aux EtatsUnis et une moyenne mondiale de $20 \mathrm{~kg} /$ tête/an.Bien que presque toutes les huiles soient partiellement substituables entre elles dans leurs différents créneaux d'utilisation, les habitudes alimentaires, de même que les politiques commerciales mises en œuvre par les grands huiliers 
internationaux, ont une grande influence sur les structures de consommation, particulièrement au niveau des achats directs par les consommateurs à des fins d'assaisonnement et de friture. Ainsi, sur le marché des ventes directes aux consommateurs, qui tend à stagner globalement depuis des années, on observe un développement important de l'huile d'olive, portée par une image nutritionnelle et gastronomique très favorable qui lui permet de compenser un prix plus élevé et d'échapper dans une large mesure à la concurrence directe des huiles de graines. Les utilisations communautaires d'huiles végétales peuvent se décomposer en achats directs par les consommateurs, utilisations en restauration hors foyer, utilisations dans les industries alimentaires (comme la margarinerie, la pâtisserie, les conserves de poissons, etc..), utilisations en alimentation animale et dans des usages non alimentaires comme le secteur de l'énergie, la savonnerie, la peinture, les lubrifiants et la lipochimie. On ne dispose pas de données précises sur la répartition de ces utilisations au niveau communautaire ; il apparaît cependant, d'un point de vue qualitatif, que l'évolution de la demande sur ces différents créneaux est très hétérogène et que, malgré les possibilités de substitution entre huiles en fonction des prix des marchés, les différents produits sont plus ou moins spécialisés sur certains segments de marché.Globalement, les huiles issues de l'agriculture (olive) ou de la trituration communautaires (huiles de graines) permettraient théoriquement de couvrir $76 \%$ de la consommation de I'UE, ce qui correspond à un déficit de 3,3 MT. En fait, pour des raisons de prix et d'adaptation des différentes huiles aux différents débouchés on observe des flux importants à l'exportation et à l'importation. Les exportations d'huiles de I'UE vers les pays tiers, qui représentent environ 2,3 MT en 2002, sont principalement constituées d'huiles de graines, à commencer par des huiles de soja et de colza avec, de façon variable selon les niveaux des récoltes communautaires, des huiles d'olive. Au contraire, à l'importation, l'essentiel du tonnage est constitué d'huiles tropicales : palme en premier lieu, mais aussi coco et palmiste. Les huiles de tournesol et d'arachide constituent l'essentiel du reste des importations. Alors que les tonnages d'huile d'arachide tendent sensiblement à diminuer compte tenu de l'érosion de cette consommation fortement concurrencée par le tournesol et plus récemment l'olive, les tonnages importés d'huile de tournesol sont en progression compte tenu de la baisse des disponibilités provenant des triturateurs de I'UE.Même si l'huile de colza continue à souffrir dans I'UE d'une image de marque peu favorable aux yeux de nombreux consommateurs, pour des raisons historiques, malgré l'intérêt nutritionnel de ces nouvelles variétés, largement reconnu à l'étranger, et notamment aux Etats-Unis qui est devenu le premier importateur mondial de cette huile sous le nom d'huile de canola, ce produit s'est trouvé de nouveaux débouchés très importants notamment dans les usages techniques en tant que complément ou substitut aux carburants pétroliers.

\section{Le colza sur le marché mondial}

\section{Productions et échanges}

Avec une production mondiale estimée à 32,5 MT en 2002 (contre 193,5 pour le soja, 33,5 pour le coton et 23,9 pour le tournesol), le colza est un des oléagineux majeurs dans le monde et a, en pourcentage, comme le soja, connu une très forte progression au cours des 10 dernières années. Cette production est largement dominée par I'UE (9,3 MT en 2002) et la Chine (10,5 MT) qui représentent à eux seuls plus de $60 \%$ de la récolte mondiale. Cependant, au niveau du commerce international, trois autres acteurs ont un rôle prépondérant. Il s'agit du Canada (3,9 MT), de I'Australie (790 000 en 2002 contre une moyenne de 1,8 MT au cours des années précédentes) et de 
l'ensemble des PECOs (2,3 MT).Le commerce mondial des graines de colza (hors commerce intracommunautaire) a porté sur 5,4 MT en 2002 (contre 54,6 MT pour le soja et 1,9 MT pour le tournesol). Les exportations mondiales sont traditionnellement dominées par les fournitures du Canada (2,3 MT en 2002) et de l'Australie (1,4 MT) alors que les importations sont surtout le fait de Japon (2,1 MT), du Pakistan (510 000 tonnes), de la Chine (620 000 tonnes en 2002 contre près de 3,0 MT en 2000) et du Mexique (0,9 MT). Sur ce marché, I'UE occupe une position particulière puisqu'elle est à la fois importatrice de plus de 600000 tonnes (en provenance des PECOs) et exportatrice de 750000 tonnes à destination du Mexique et du Pakistan.

Tableau 1. Bilan en graines oléagineuses de l'UE en 2002

\begin{tabular}{||l|l|l|l|l|}
\hline \hline & Productions & Importations (a) & Exportations (a) & Trituration \\
\hline Colza & 9338 & 619 & 753 & 8888 \\
\hline Soja & 915 & 18003 & 58 & 17061 \\
\hline Tournesol & 2808 & 1363 & 28 & 3559 \\
\hline Coton & 785 & 143 & 23 & 830 \\
\hline Lin & 83 & 638 & 9 & 580 \\
\hline Arachide & 1 & 521 & 25 & 38 \\
\hline Autres & 0 & 134 & 602 & \\
\hline Total & 13930 & 21421 & & 303 \\
\hline
\end{tabular}

Source : Oil World

Unité : Milliers de tonnes

(a) : Commerce intra-communautaire non compris.

Tableau 2. Bilan en tourteaux de I'UE en 2002

\begin{tabular}{|c|c|c|c|c|}
\hline & Productions & Importations (a) & Exportations (a) & Consommations \\
\hline Colza & 5080 & 489 & 47 & 5522 \\
\hline Soja & 13489 & 19569 & 2331 & 30727 \\
\hline
\end{tabular}




\begin{tabular}{||l|l|l|l|l|}
\hline Tournesol & 1872 & 1281 & 13 & 3140 \\
\hline Coton & 436 & 166 & 8 & 594 \\
\hline Lin & 359 & 18 & 3 & 145 \\
\hline Arachide & 16 & 129 & 0 & 2778 \\
\hline Palmiste/coprah & 10 & 2770 & 1 & 17 \\
\hline Autres & 8 & 10 & 2405 & 43297 \\
\hline Total & 21270 & 24432 & & \\
\hline
\end{tabular}

Source : Oil World

Unité : Milliers de tonnes

(a) : Commerce intra-communautaire non compris

Tableau 3. Bilan de I'UE en huiles en 2002

\begin{tabular}{|c|c|c|c|c|}
\hline & Productions & Importations (a) & Exportations (a) & Consommations \\
\hline Colza & 3697 & 7 & 410 & 3356 \\
\hline Soja & 3149 & 15 & 1088 & 2094 \\
\hline Tournesol & 1470 & 606 & 117 & 1922 \\
\hline Coton & 123 & 8 & 9 & 122 \\
\hline Lin & 191 & 3 & 49 & 144 \\
\hline Arachide & 10 & 147 & 8 & 155 \\
\hline Autres & 20 & 1 & 1 & 20 \\
\hline Huiles de graines & 8660 & 787 & 1682 & 7813 \\
\hline Olive & 2191 & 38 & 374 & 1950 \\
\hline Palme & 0 & 3340 & 130 & 3211 \\
\hline
\end{tabular}




\begin{tabular}{|l|l|l|l|l|}
\hline Palmiste/coco & 18 & 1285 & 79 & 1217 \\
\hline $\begin{array}{l}\text { Total huiles } \\
\text { végétales }\end{array}$ & 10869 & 5450 & 2265 & 14191 \\
\hline
\end{tabular}

Source : Oil World

Unité : Milliers de tonnes

(a) : Commerce intra-communautaire non compris

Au niveau du tourteau, l'UE a importé en 2002 près de 500000 tonnes sur un total d'environ 2,0 MT. Outre les importations croissantes de la Thaïlande et de la Corée du Sud, le phénomène important à souligner est la place très importante des Etats-Unis qui, avec plus de 800000 tonnes en 2002 (provenant presque exclusivement du Canada), demeurent le premier importateur mondial. Pour ces approvisionnements en tourteau de colza, I'UE s'est massivement tournée vers les PECOs, abandonnant depuis des années les produits originaires du Canada en raison de l'adoption, par ce pays, de variétés OGM de canola.Sur le marché mondial des huiles de colza qui représente 1,3 MT en 2002 (contre 25 MT pour le palme, 9,2 pour le soja et 2,2 pour le tournesol), I'UE occupe une position notable en tant que second exportateur avec 410000 tonnes derrière le Canada (540 000 tonnes). Le principal débouché de l'UE pour cette huile est actuellement l'Algérie, mais avait surtout concerné I'Inde, le Pakistan et la Russie, il y a quelques années.

\section{Prix internationaux des produits du colza}

Au cours des années 1999 à 2002, les prix de la graine de soja US CAF Rotterdam ont connu leur plus bas niveau depuis 1972. Avec environ $200 \$ /$ tonne, ce niveau se situe à plus de $20 \%$ en dessous de la moyenne des trente dernières années. Cet effondrement des prix mondiaux du soja, malgré la très forte progression de la demande de la Chine et de différents pays asiatiques et sud-américains, coïncide avec la forte progression des surfaces du Brésil et de l'Argentine, mais aussi avec la mise en place de la nouvelle réglementation des États-Unis, qui depuis le Fair Act, en raison de l'introduction des Marketing Loans n'assure plus aucun prix minimum au niveau mondial. Dans le cadre de cette nouvelle loi, prolongée par la loi de 2002, les soutiens antérieurs par les prix aux producteurs de soja des Etats-Unis se trouvent remplacés par des aides aux revenus à travers notamment des paiements couplés (Loan Deficiency Payments et Emergency Payments).La baisse des prix mondiaux des graines de soja (figure 7) s'est accompagnée pour l'essentiel de baisses de prix pour les graines de colza (Europe 00 CAF Hambourg) et de tournesol (Europe CAF Lower Rhine). Cependant, l'influence des prix des tourteaux et des huiles n'étant pas la même pour les trois graines d'une part, et d'autre part les rapport de prix entre les différents tourteaux et les différentes huiles pouvant évoluer au cours du temps, les rapports de prix entre la graine de soja et les graines oléagineuses communautaires ont également fortement changé au cours des dernières années.Par rapport à une moyenne de prix relative au soja sur les trente dernières années de $104 \%$ pour la graine de colza et de $111 \%$ pour le tournesol, les ratios sont en 2002 de 110 pour le colza et de 135 pour le tournesol, ce ratio étant le plus élevé jamais enregistré pour cette graine.Comme pour les graines, les prix des tourteaux sont revenus à des niveaux très faibles depuis 1997, malgré de légères reprises au cours des trois dernières années. Les tourteaux de colza (FOB Dutch ex Mill) et de tournesol (Argentine CAF Rotterdam) ont naturellement été entraînés à la baisse par le tourteau de soja. 
En moyenne au cours des 30 dernières années le prix du tourteau de colza a représenté $67 \%$ de celui du soja et le tourteau de tournesol $62 \%$, ce qui s'explique largement par les différences de teneur en protéine de ces produits et de composition en acides aminés de ces protéines. II n'en reste pas moins que, depuis le début des années 90 , alors que le prix relatif du tourteau de colza tendait à se stabiliser autour de $65 \%$, le prix du tourteau de tournesol s'est fortement dégradé en dessous de la barre des $55 \%$. Ce phénomène s'explique principalement par le fait que l'activité des unités de trituration communautaires de colza et de tournesol est surtout régulée par la demande d'huile, le tourteau étant alors un co-produit qui doit être commercialisé rapidement pour éviter la constitution de stocks. Le rapport de prix des tourteaux de colza et de tournesol qui avait fortement chuté au cours des années 80 où, avec l'expansion des récoltes communautaires de colza et de tournesol, la trituration avait connu un fort développement, tend depuis que ces productions de graines sont relativement stagnantes, voire en régression, à retrouver des niveaux plus élevés.

Au niveau des huiles végétales, le palme et surtout le soja constituent les deux produits leaders et tendent à imposer leurs évolutions aux autres produits du secteur. En 2000, 2001 et, dans une moindre mesure 2002, ces prix ont été particulièrement faibles, revenant pour certains d'entre eux à leur plus bas niveau depuis 20 ans en raison de la forte abondance de ces huiles sur le marché mondial.

En moyenne sur les trente dernières années (figure 11), le prix de l'huile de palme a représenté $92 \%$ de celui du soja alors que le colza était à l'indice 97 et le tournesol à l'indice 113. En fait ces ratios peuvent évoluer très fortement selon les années. Après plusieurs années de très forte progression des productions de palme en Malaisie et en Indonésie, les tonnages de ce produit obtenus et échangés dans le monde ont eu tendance à progresser moins rapidement, faisant passer le prix relatif de cette huile par rapport au soja à 107 en 1998. Depuis, le prix relatif du palme est à nouveau orienté à la baisse et le ratio est de 85 en 2002.

Pour l'huile de tournesol qui reste pratiquement toujours l'huile la plus chère des quatre produits considérés, après une période de forte diminution des différentiels de prix par rapport au soja et au colza qui a duré de 1983 à 1997, le ratio a, par la suite, très fortement augmenté pour dépasser l'indice 130 en 2001 et 2002 en raison de la diminution des récoltes et des triturations de cette graine dans I'UE, obligeant les huiliers à s'approvisionner plus fortement sur un marché mondial par ailleurs déséquilibré par la diminution des récoltes de l'Argentine.

Enfin pour l'huile de colza, le prix relatif est longtemps resté légèrement en dessous du seuil des 100 avec de faibles variations d'une année sur l'autre. Depuis trois ans la forte demande de ce produit pour le non alimentaire, jointe à un accroissement de la demande par les industries alimentaires a entraîné un net renchérissement de ce produit par rapport au soja (106 en 2002 contre 91 en 1991). Le colza bénéficie également des fortes réticences de nombreux utilisateurs par rapport au produit du soja susceptible de provenir de graines contenant des OGM.

\section{Conclusions}

Avec plus de 3 millions d'hectares dans I'UE en 2002, le colza constitue une culture de grande importance derrière le blé (environ 17,7 Mha en 2002), l'orge (10,6 Mha) et le maïs (4,4 Mha). 
Compte tenu de I'OCM qui s'applique depuis le début des années 60 aux produits oléagineux dans I'UE, à savoir la libre importation sans aucune limite quantitative, ni pratiquement aucun droit de douane sur les graines, les tourteaux et les huiles, ces produits se trouvent directement en prise avec les marchés mondiaux, alors que pour les céréales, malgré les baisses répétées des prix d'intervention, demeurent certains mécanismes de soutien des prix. Alors qu'entre 1984 et 1994, les surfaces des 15 pays actuels de l'UE en oléagineux avaient pratiquement doublé, passant d'environ 3 à 6 millions d'hectares, elles ont depuis lors régressé de près d'un million d'hectares. La légère progression des surfaces en colza (+300 000 ha) n'a en effet pas permis de compenser le net recul du soja qui est revenu à moins de 300000 ha en 2002 (- 240000 ha par rapport au pic enregistré en 1998), ni surtout du tournesol qui est revenu à 1,7 million d'hectares, son plus bas niveau depuis 1984, contre un maximum de 2,9 en 1994. Le colza représente donc en 2002 plus de $60 \%$ des surfaces en oléagineux (hors coton et lin) cultivés dans l'UE.

Depuis 1997 pour les tourteaux et 1999 pour les huiles, les prix des produits du colza ont connu dans I'UE comme sur le marché international de fortes baisses. Ainsi pour le tourteau le prix FOB Dutch ex Mill a chuté de 188 \$/tonne en 1996 à 107 \$/tonne (-43\%) avant de reprendre légèrement au cours des trois dernières années (127 \$/tonne en moyenne en 2002). De même pour l'huile de colza le prix Hambourg FOB ex Mill est passé de 628 \$/tonne en 1998 à 347 en 2000 (-45\%) avant de reprendre sensiblement au cours des deux dernières années (485\$/tonne en 2002). Les produits du colza ont donc essentiellement subi l'influence des cours mondiaux du soja et du palme ; cependant, faisant I'objet d'une demande spécifique sur le marché de l'UE, ils ont bénéficié d'une certaine amélioration de leur ratio de prix par rapport au soja.

Le colza présente donc un ensemble d'avantages pour l'agriculture et les utilisateurs de I'UE. D'une part il constitue une alternative aux importations de tourteaux et d'huiles et permet une meilleure traçabilité, facteur auquel les consommateurs sont de plus en plus sensibles, d'autant plus que les grands pays fournisseurs (Etats-Unis, Argentine, Canada) sont massivement passés aux cultures de plantes OGM pour le soja et le colza. Ensuite, il permet à l'UE, même si ces dérivés ne constituent qu'une partie limitée des consommations communautaires, d'avoir une certaine crédibilité au niveau des négociations internationales et de n'être pas totalement dépendante des politiques agricoles mises en place dans certains pays producteurs - exportateurs, à commencer par les Etats-Unis. Alors qu'en UE, depuis la mise en place de l'Agenda 2000, les graines oléagineuses ont subit un découplage "vers le bas" avec un abaissement des aides directes pour ces produits au niveau de celles attribuées aux céréales, aux Etats-Unis, depuis le Fair Act de 1996, ces mécanismes étant maintenus dans la nouvelle loi de 2002, le soja comme les autres oléagineux bénéficie d'un découplage "vers le haut ", avec l'attribution à ces produits des mêmes avantages que pour les céréales. Alors que la production d'oléagineux dans I'UE a été durant une longue période bloquée par les surfaces maximum garanties issues de Blair House, les Etats-Unis ont entrepris depuis 1996 une forte reconquête de leurs parts de marché dans le commerce international des graines et tourteaux de soja et cherchent à se positionner comme principal fournisseur potentiel de la Chine qui a adhéré à I'OMC et dont les besoins futurs apparaissent considérables. Entre 1997/1998 et 2002/2003, les importations de graines de soja de ce pays ont été multipliées par 6 et, avec près de 18 millions de tonnes, il devrait devenir, au cours de cette dernière campagne, le premier importateur mondial devant l'UE (16,9 MT). Face à l'importance de la demande future prévisible de ces nouveaux clients d'Asie et d'Amérique du Sud, I'UE ne constitue plus la cible privilégiée des grands exportateurs, en termes de satisfaction des besoins locaux au niveau quantitatif et qualitatif. Les cours mondiaux très 
faibles qui ont été observés durant les dernières années semblent donc correspondre plus à une situation conjoncturelle, liée en partie à la politique des Etats-Unis qui ont privilégié le soja pour conquérir de nouveaux marchés, qu'à une situation structurelle.

Face à ces incertitudes pour le moyen et le long terme, l'UE se doit d'utiliser les différents moyens compatibles avec ses accords internationaux pour conforter sa situation de producteur d'oléagineux. Une telle orientation passe d'abord par des efforts de recherche importants pour rendre moins variables et améliorer les rendements de la culture du colza à un rythme au moins égal à ceux des céréales. Elle passe ensuite par l'amélioration de la composition de cette graine, notamment au niveau de son huile et de ses protéines pour améliorer leur compétitivité par rapport aux produits leaders (tourteau de soja et huiles de palme et de soja) et aussi pour rendre ses produits plus adaptés à certains créneaux nouveaux (notamment dans le secteur non alimentaire). Un troisième enjeu pour le colza est la véritable prise en compte, dans la réglementation communautaire, des avantages environnementaux que peut fournir cette plante notamment en termes de maintien d'une diversification des assolements permettant d'éviter une trop grande dépendance de l'agriculture européenne par rapport au blé dont les marchés mondiaux restent aléatoires.

\section{Illustrations}

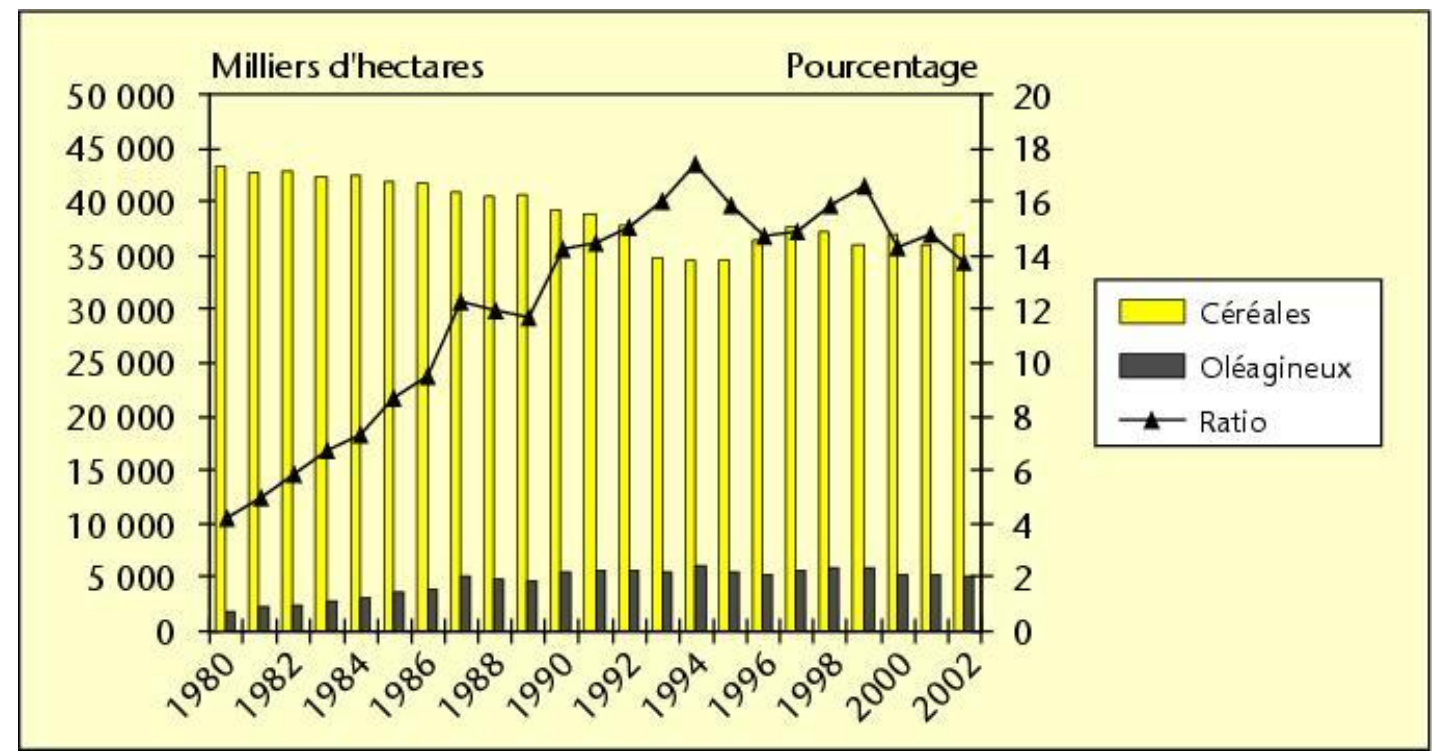

Figure 1. Évolution des surfaces en oléagineux et céréales dans I'UE (milliers d'hectares). 


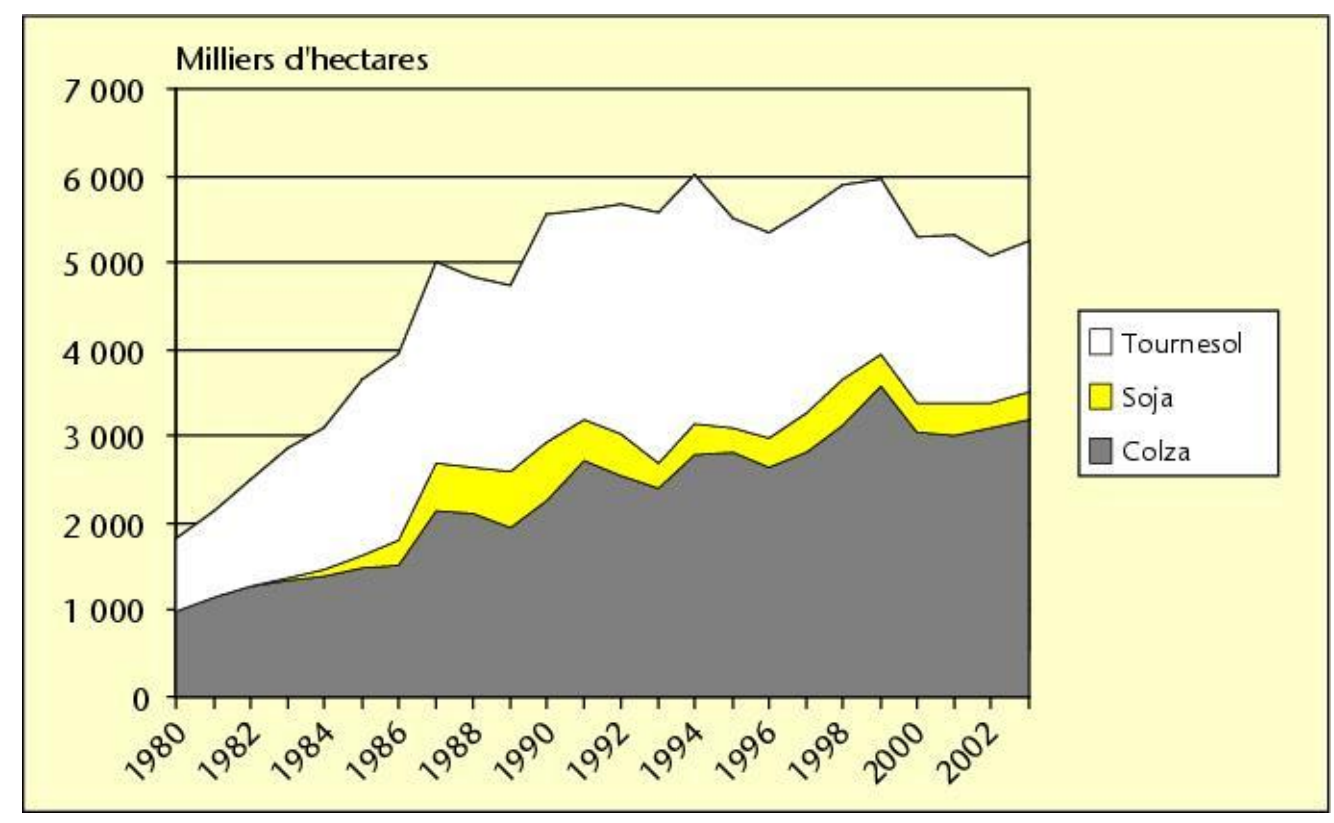

Figure 2. Évolution des différentes surfaces en oléagineux (milliers d'hectares).

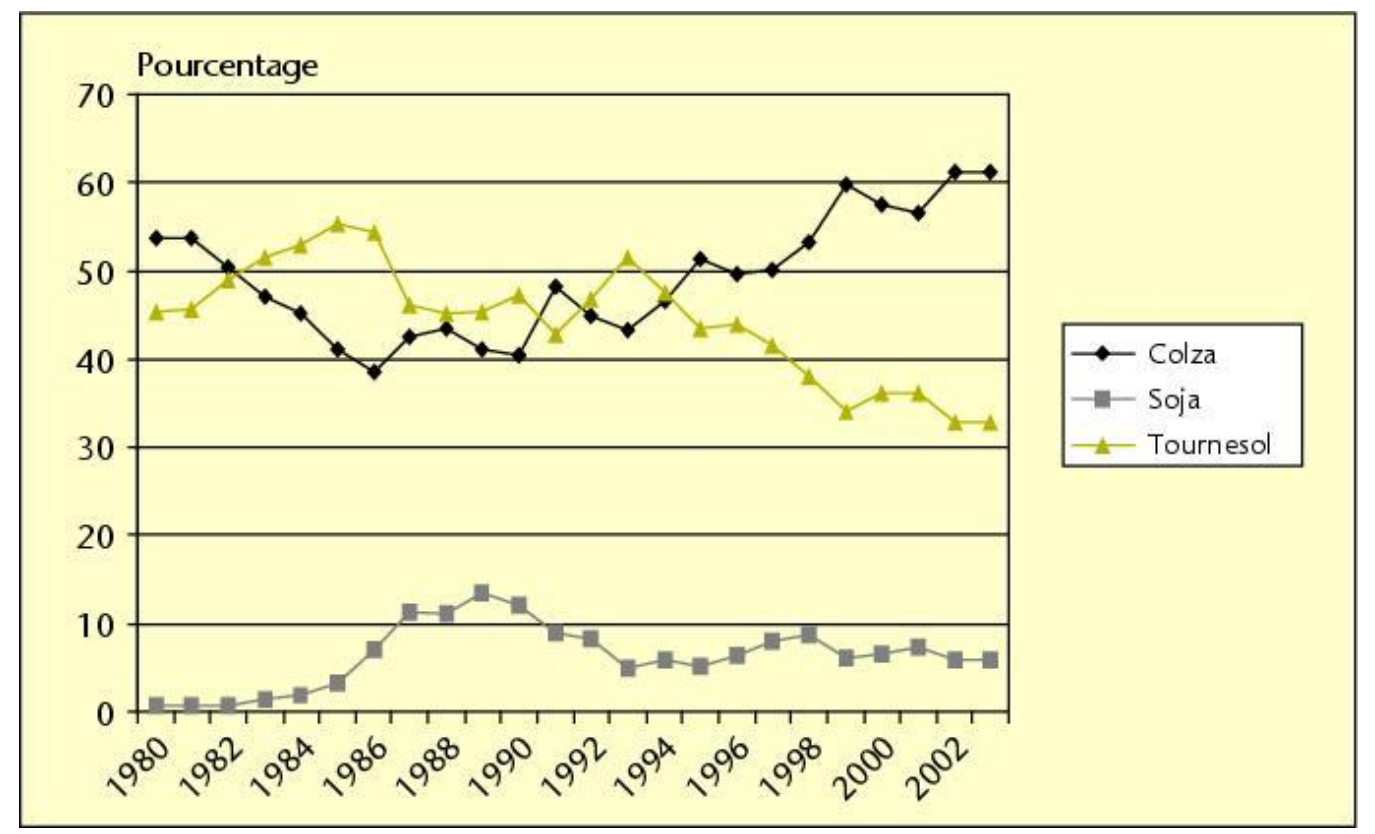

Figure 3. Évolution de la répartition des surfaces en oléagineux dans I'UE (pourcentages). 


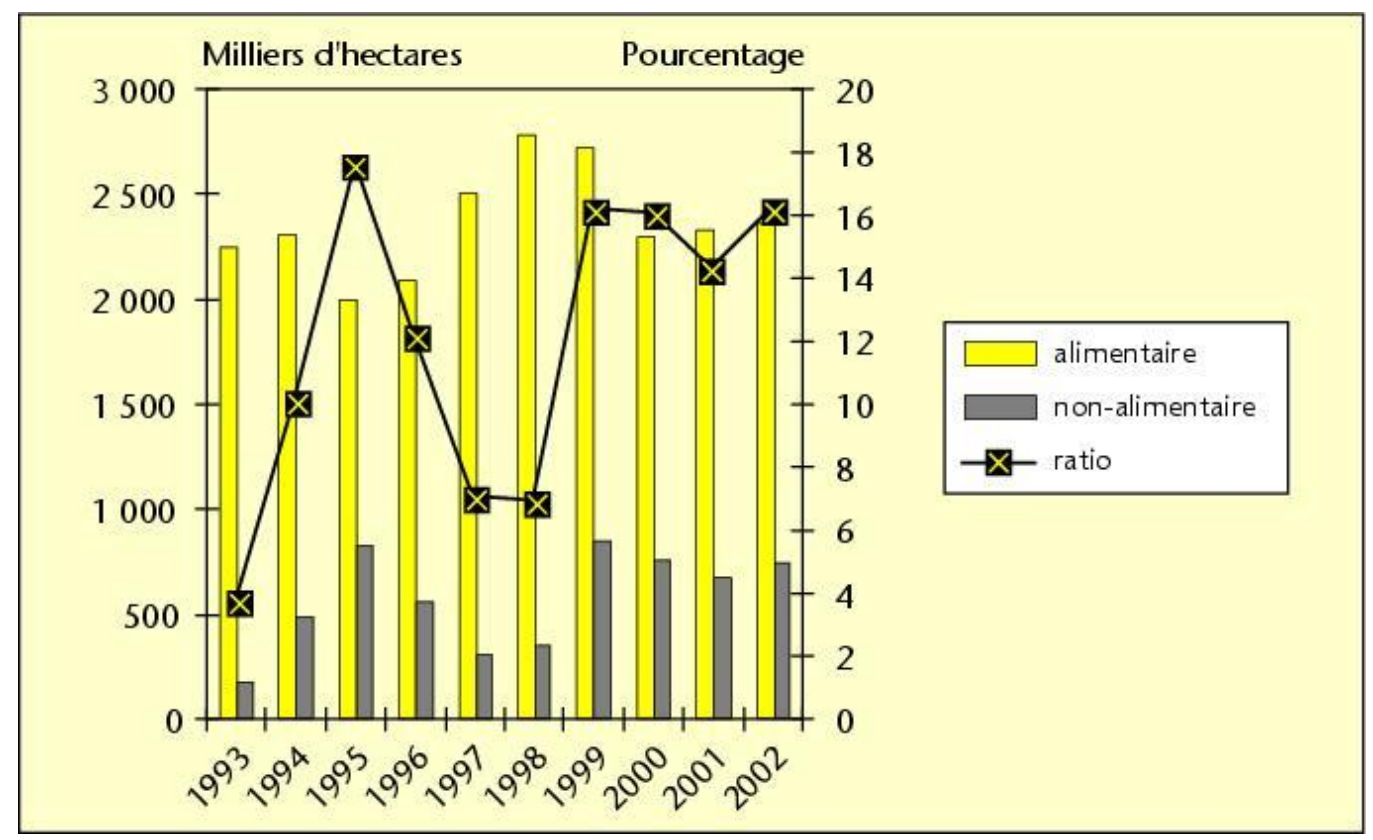

Figure 4. Évolution des surfaces en colza : alimentaire et non-alimentaire dans I'UE (milliers d'hectares)

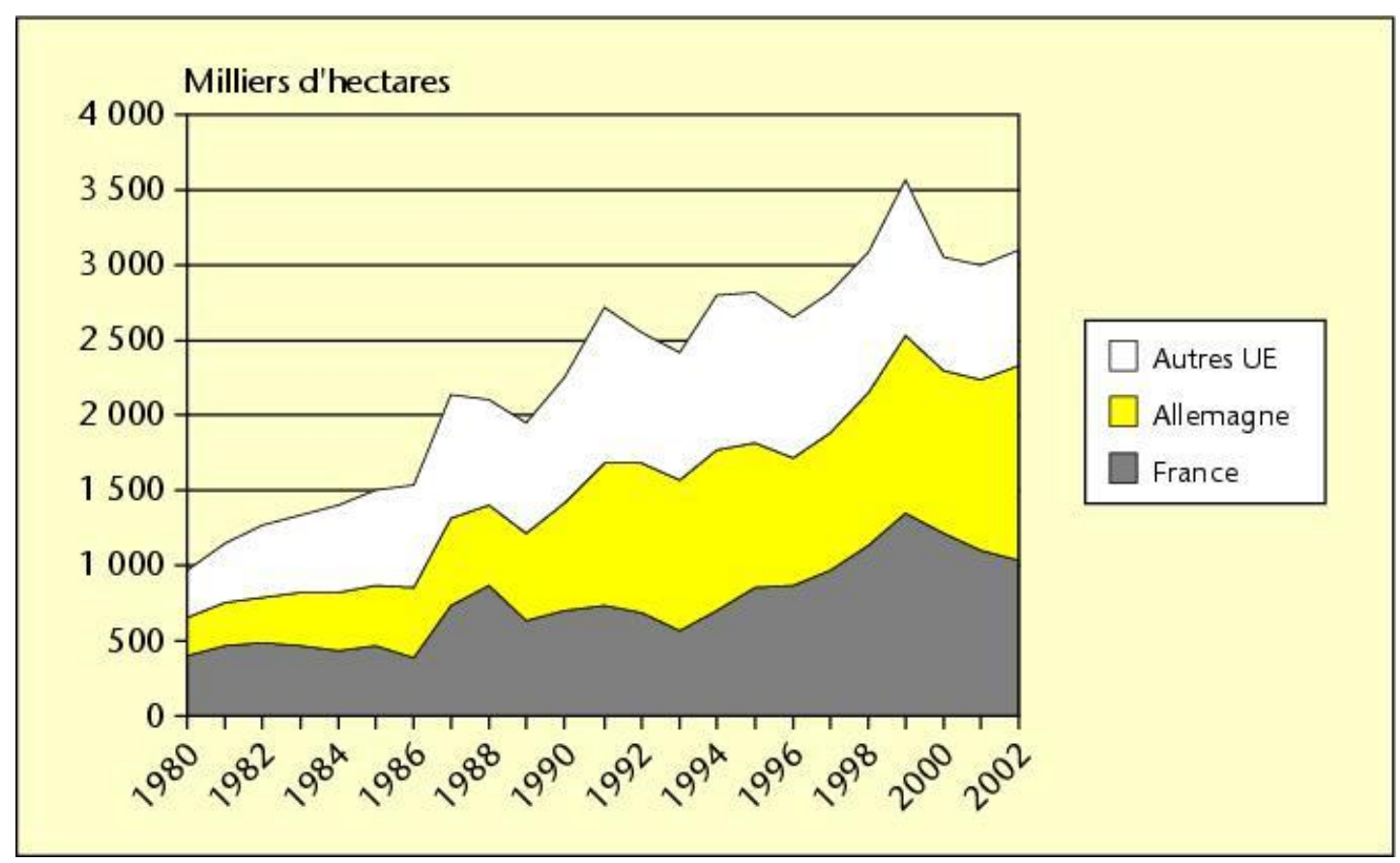

Figure 5. Évolution des surfaces en colza des principaux pays de I'UE (milliers d'hectares). 


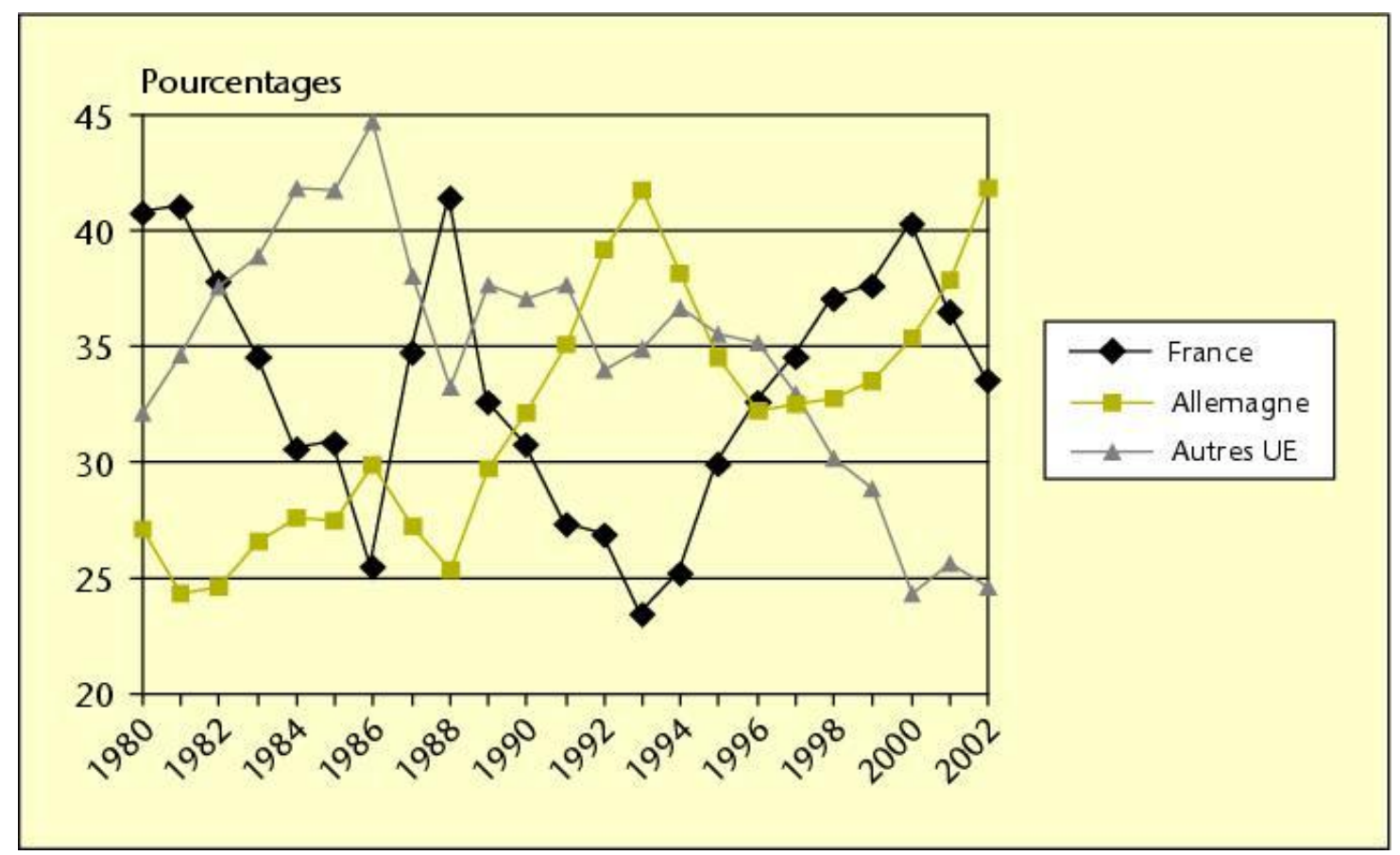

Figure 6. Évolution de la place des principaux pays dans les superficies de l'UE en colza (pourcentages).

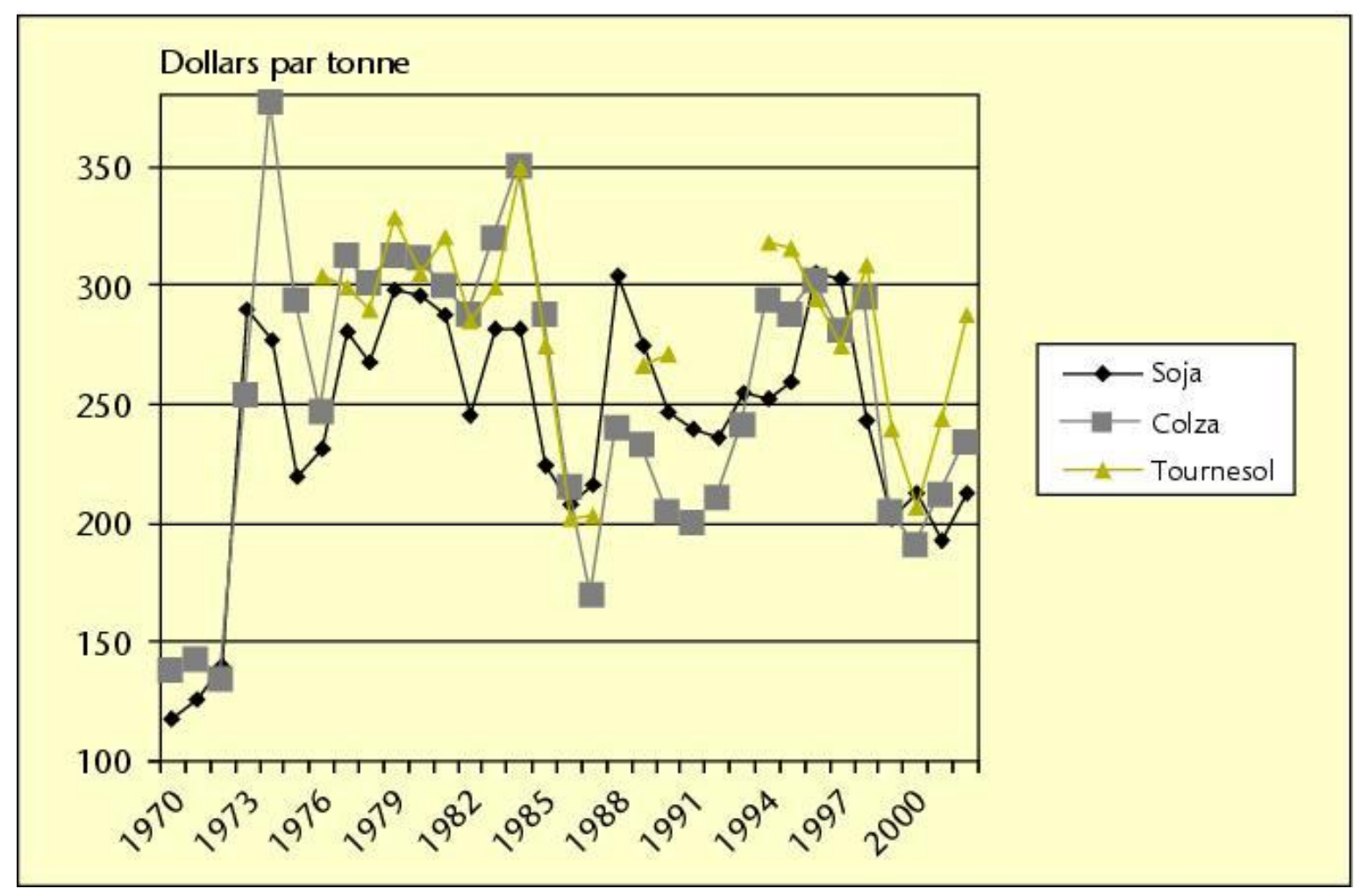

Figure 7. Évolution des prix des graines oléagineuses (dollars par tonne). 


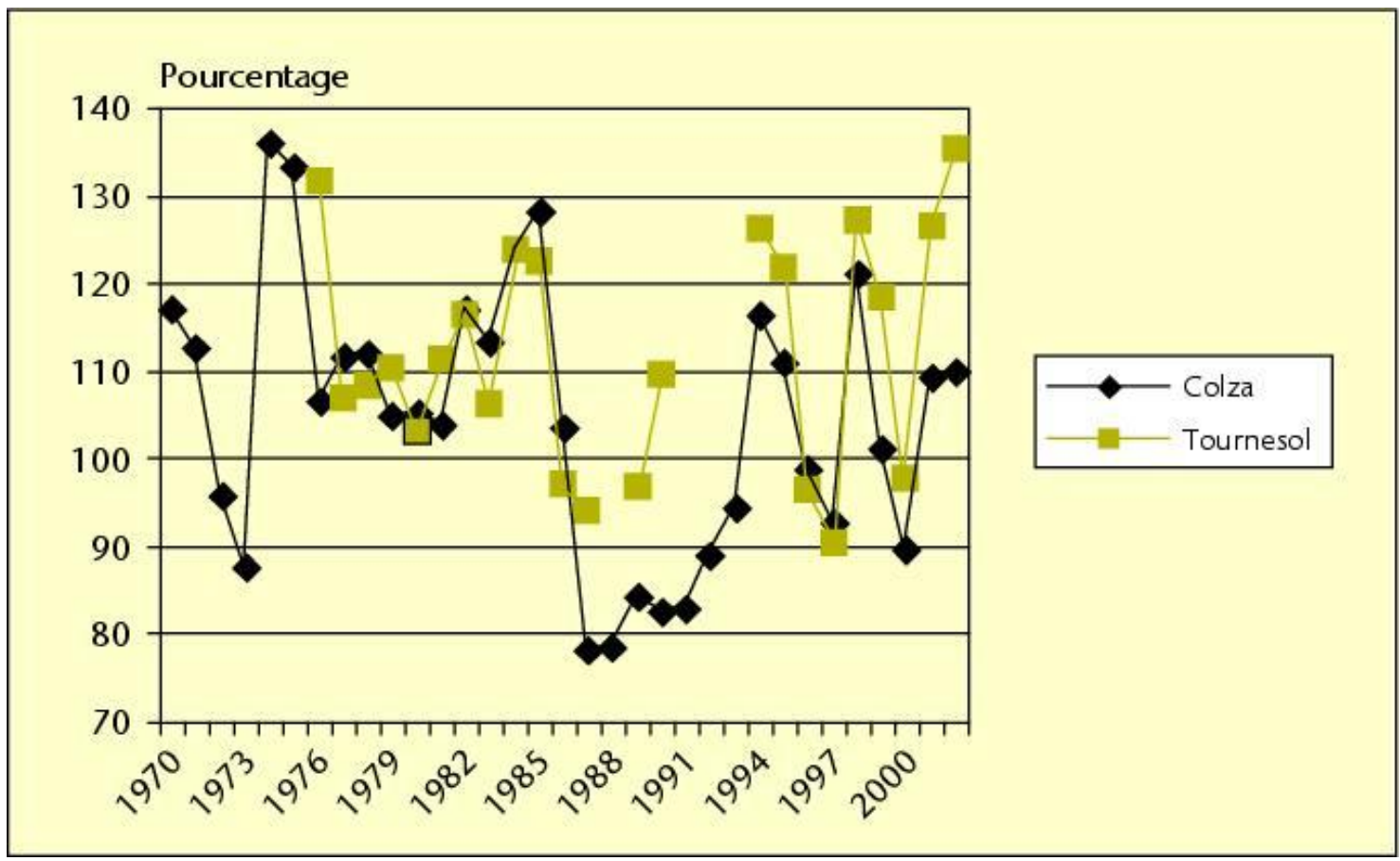

Figure 8. Évolution des prix relatifs des graines oléagineuses (graine de soja base 100).

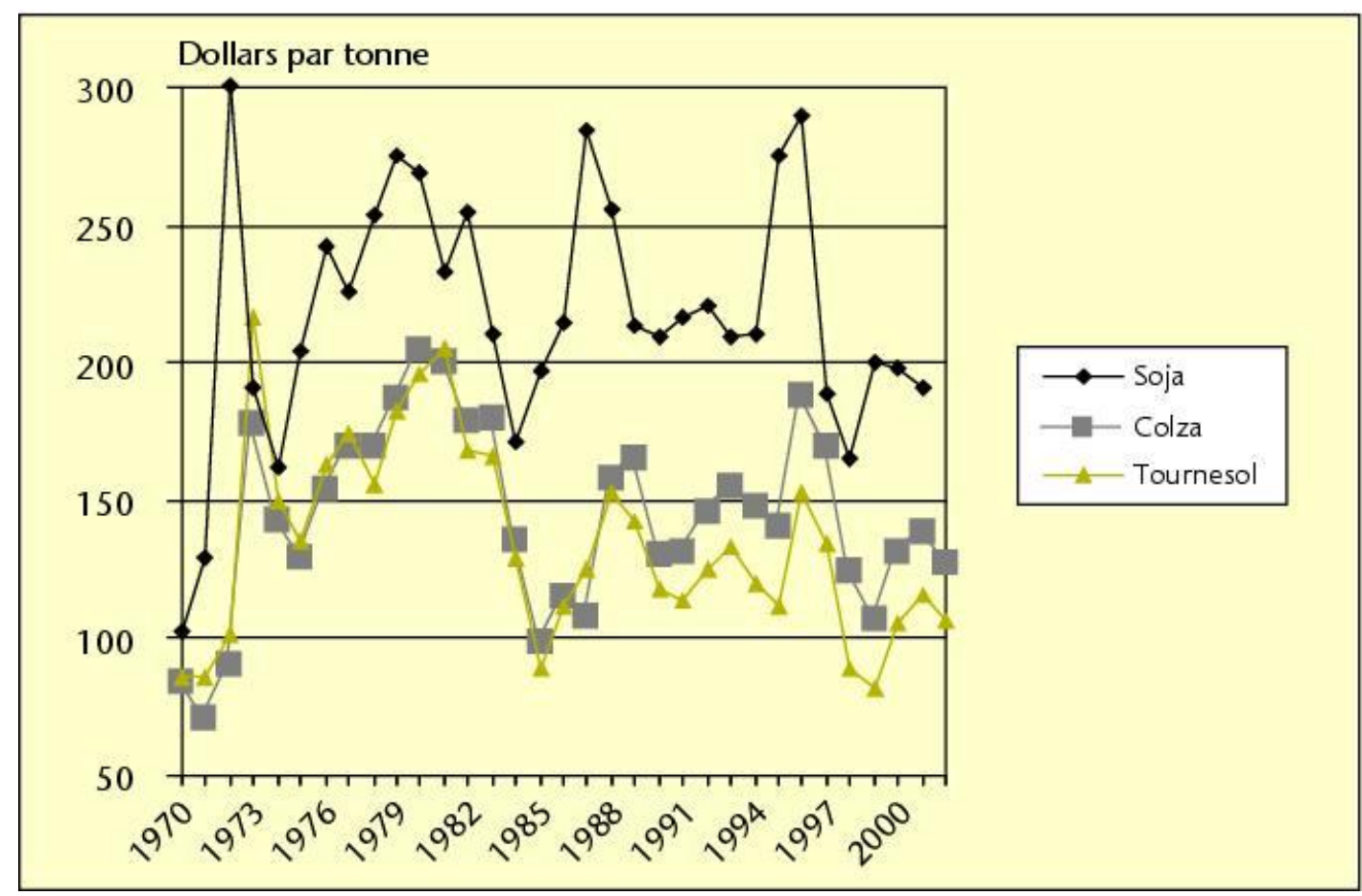

Figure 9. Évolution des prix des principaux tourteaux (dollars par tonne). 


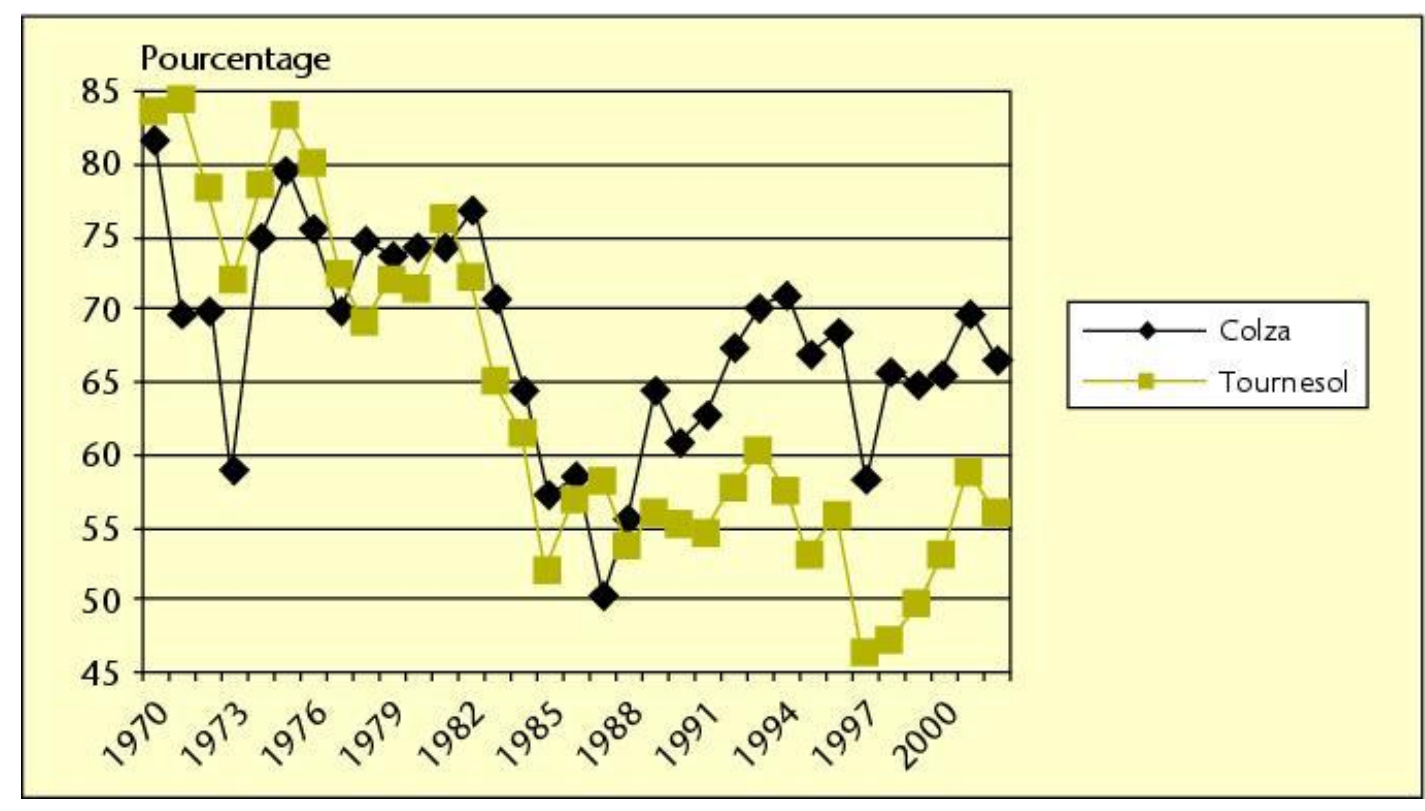

Figure 10. Évolution des prix relatifs des principaux tourteaux (tourteau de soja base 100).

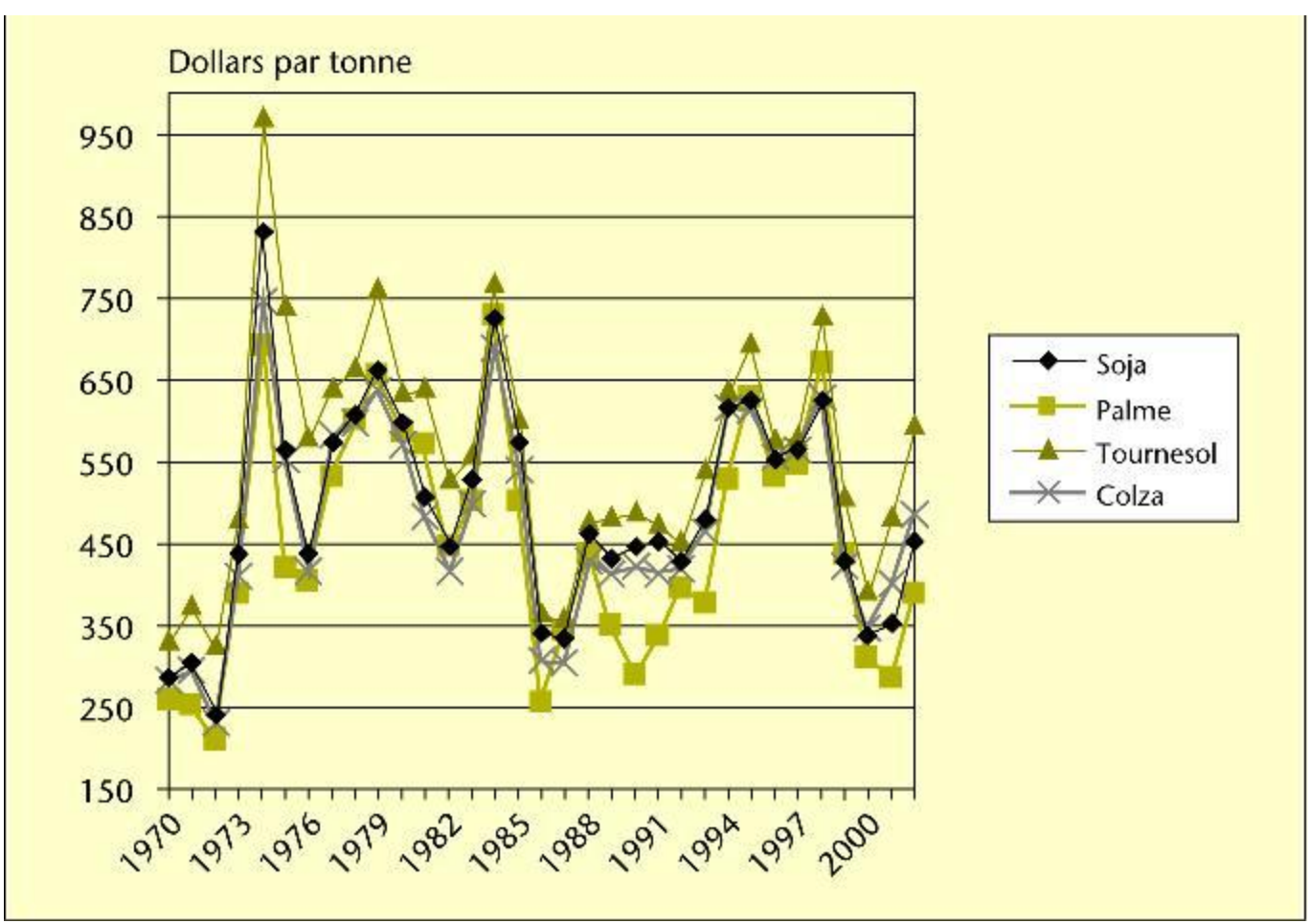

Figure 11. Évolution des prix des principales huiles végétales (dollars par tonne). 


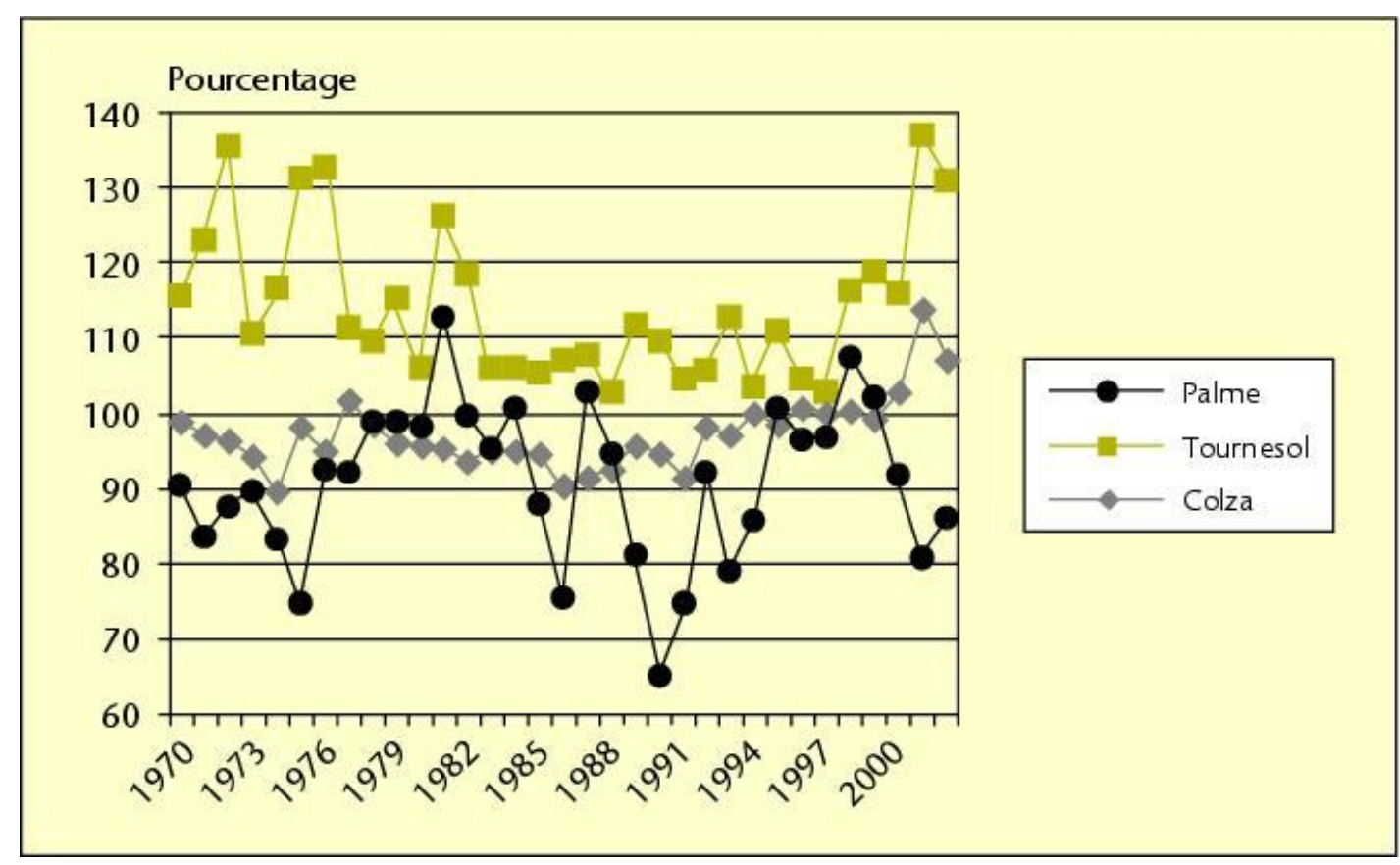

Figure 12. Évolution des prix relatifs des principales huiles végétales (huile de soja base 100). 